\title{
Influence of thermal fronts on habitat selection by four rorqual whale species in the Gulf of St. Lawrence
}

\author{
Thomas Doniol-Valcroze ${ }^{1,2,3, *}$, Dominique Berteaux ${ }^{3}$, Pierre Larouche ${ }^{4}$, Richard Sears ${ }^{2}$ \\ ${ }^{1}$ Department of Natural Resource Sciences, McGill University, 21111 Lakeshore Road, Ste.-Anne-de-Bellevue, \\ Quebec H9X 3V9, Canada \\ ${ }^{2}$ Mingan Island Cetacean Study, 285 Green, St. Lambert, Quebec J4P 1T3, Canada \\ ${ }^{3}$ Canada Research Chair in Conservation of Northern Ecosystems and Centre d'etudes nordiques, \\ Université du Québec à Rimouski, 300 allée des Ursulines, Rimouski, Quebec G5L 3A1, Canada \\ ${ }^{4}$ Institut Maurice-Lamontagne, 850 route de la Mer, PO Box 1000, Mont-Joli, Quebec G5H 3Z4, Canada
}

\begin{abstract}
Understanding the factors influencing habitat selection is critical to improving management and conservation plans for large whales. Many studies have linked the distribution of cetaceans to basic environmental features such as underwater topography and sea surface temperature (SST), but the mechanisms underlying these relationships are poorly understood. Dynamic mesoscale processes like thermal fronts are prime candidates to link physiographic factors to whale distribution because they increase biological productivity and aggregate prey. However, previous studies of large whales have found little evidence of such associations, possibly because they were not at the appropriate spatio-temporal scales. We quantified the relationship between SST fronts and the distribution of blue Balaenoptera musculus, finback B. physalus, humpback Megaptera novaeangliae and minke B. acutorostrata whales in the northern Gulf of St. Lawrence. We compared the distribution of 1094 whale sightings collected from boat surveys conducted in 1996 to 2000 to the locations of frontal areas determined from 61 satellite maps. The distributions of whales and thermal fronts were highly correlated (random resampling and Mantel tests of matrix similarity). Spatial distributions differed among species, probably reflecting differences in feeding strategies. Identification of surface fronts from satellite imagery thus effectively complemented field observations of whales. These findings significantly increase our understanding of habitat quality in rorqual whales, and encourage a greater use of dynamic environmental variables in future studies of whale habitat use.
\end{abstract}

KEY WORDS: Sea surface temperature $\cdot$ Thermal fronts $\cdot$ Blue whale $\cdot$ Finback whale $\cdot$ Humpback whale $\cdot$ Minke whale $\cdot$ Habitat selection $\cdot$ Gulf of St. Lawrence

Resale or republication not permitted without written consent of the publisher

\section{INTRODUCTION}

Successful management of cetacean populations requires information on their foraging habitats (Bjørge 2002). Therefore, a growing number of studies quantify relationships between habitat use and basic environmental features in order to generate prediction models of marine mammal distribution (e.g. Gregr \& Trites 2001, Hamazaki 2002). Model predictors are often chosen based on their availability, although choice of variables should rather derive from ecologi- cal theory (Gregr 2004). Common predictors of cetacean distribution include sea surface temperature (SST), distance to shore, and underwater topography (e.g. Hoelzel et al. 1989, Woodley \& Gaskin 1996) but the mechanisms linking these variables to patterns of habitat selection have begun to be investigated only recently (e.g. Croll et al. 2005). Nevertheless, identifying cause-effect relationships in ecological models is critical (Hilborn \& Mengel 1997).

The distribution of rorqual whales on their feeding grounds is mostly related to the abundance and patch- 
iness of krill (Murase et al. 2002) and fishes (Whitehead \& Carscadden 1985). Patchiness of organisms in coastal ecosystems is often caused by the dynamic features of mesoscale oceanographic processes like fronts, eddies and upwellings (Olson \& Backus 1985). These processes usually involve spatial scales of 1 to $10 \mathrm{~km}$ and temporal scales of 1 to $10 \mathrm{~d}$ (Hofmann \& Powell 1998). In most cases, when these upwellings reach the surface, one of their manifestations is a thermal gradient between warm surface waters and cold upwelled waters. Such mesoscale oceanographic processes increase biological productivity and aggregate prey species (Olson \& Backus 1985), thus influencing the distribution of several pelagic fish species (e.g. Fiedler \& Bernard 1987, Podesta et al. 1993).

Gaskin (1987) predicted that these transition zones between tidally mixed and thermally stratified areas could be an important feature of right whale habitat in the lower Bay of Fundy. This hypothesis was supported by some anecdotal evidence (Murison \& Gaskin 1989) but not by quantitative results (Woodley \& Gaskin 1996). Similarly, Baumgartner et al. (2003) suggested that spatial and interannual variability in right whale occurrence on the Scotian shelf may be associated with SST gradients, but Baumgartner \& Mate (2005) found no evidence that tagged right whales associated with such fronts. Several cetacean species do concentrate near mesoscale features and coastal upwelling areas (e.g. Monterey Bay, Benson et al. 2002; Gulf of Mexico, Davis et al. 2002) but specific information on rorqual whales is very scarce. Hamazaki (2002) showed that rorqual abundance was related to areas with higher monthly probability of front occurrence but this relationship was never investigated spatially, nor at a finer time-scale.

Long-term studies of rorqual whales in the northern Gulf of St. Lawrence (Quebec, Canada) have shown that distribution of blue Balaenoptera musculus, finback $B$. physalus, humpback Megaptera novaeangliae and minke $B$. acutorostrata whales is linked to areas of heterogeneous sea-bottom topography (T. DoniolValcroze \& R. Sears unpubl. data). Naud et al. (2003) found a similar relationship for minke whales studied in a subset of the same research area, and therefore this link appears strong across several spatial scales (1 to $10 \mathrm{~km}$ grid cells). However, these studies also showed significant variation in time that could not be explained by static bathymetric factors. Satellite remote sensing shows that surface temperature in the St. Lawrence is strongly influenced by tidal mixing and upwellings and can vary quickly (Thibault et al. 2002). Such mesoscale processes could provide additional explanation for the temporal variability observed in whale habitat use. Because these upwellings can be induced by local changes in sea-bottom topography
(Hui 1985, Marchand et al. 1999), the resulting thermal fronts might constitute an important link between physiographic factors and whale distribution patterns.

Here we consider the influence of a dynamic oceanographic feature on habitat selection of rorqual whales through the use of biological (whale sightings) and physical (satellite-derived SST) data collected at fine spatial and temporal scales. We test the hypothesis that spatio-temporal distribution of 4 species of rorqual whales in the northern Gulf of St. Lawrence is related to thermal fronts. More specifically, we predict that whales should be found closer to SST fronts than expected under a random scenario, and that betweenspecies differences should reflect species-specific feeding strategies.

\section{MATERIALS AND METHODS}

Study area. We worked on the North Shore of the Gulf of St. Lawrence, in the Strait of Jacques Cartier between the Mingan Islands and Anticosti Island (Fig. 1). This region of the Gulf is characterised by wind-driven upwellings during the summer, heavy tidal mixing and high levels of biological productivity (Koutitonsky \& Bugden 1991). Aerial surveys showed that the North Shore shelf had the greatest cetacean species diversity of the entire St. Lawrence (Kingsley \& Reeves 1998).

Data collection. Personnel from the Mingan Island Cetacean Study (MICS) conducted field work from June to October 1996 to 2000 using $7 \mathrm{~m}$ long rigidhulled inflatable boats with outboard engines of 90 to $200 \mathrm{hp}$. As part of a photo-identification study, survey boats tried to cover the largest possible area every day and spent more time in areas where whales were frequently encountered. Although our sampling was neither random nor systematic, surveys incorporated a broad range of habitat variability and were performed blindly with respect to the location of frontal areas. Total distance covered in a day could be up to $220 \mathrm{~km}$ $($ mean $=112 \mathrm{~km}, \mathrm{SE}=34 \mathrm{~km})$ and average surveying effort was $10338 \mathrm{~km}(\mathrm{SE}=1022 \mathrm{~km})$ per year. Field work was highly dependent on weather conditions. Due to westerly prevailing winds, we spent more time in the western half of the research area than in the eastern half. Survey and research activities were possible if wind speed was $\leq 20$ knots $\left(37 \mathrm{~km} \mathrm{~h}^{-1}\right)$, sea state $\leq 5$ on the Beaufort scale, and visibility $\geq 6 \mathrm{~km}$. We spotted whales at a distance of up to $5 \mathrm{~km}$ in good conditions. We obtained the latitude and longitude of each sighting of blue, fin, humpback and minke whales by recording the position where the whale dove at the end of its surface sequence (i.e. its 'footprint') with a GPS (precision $\leq 30 \mathrm{~m}$ ). To avoid biases due to some 


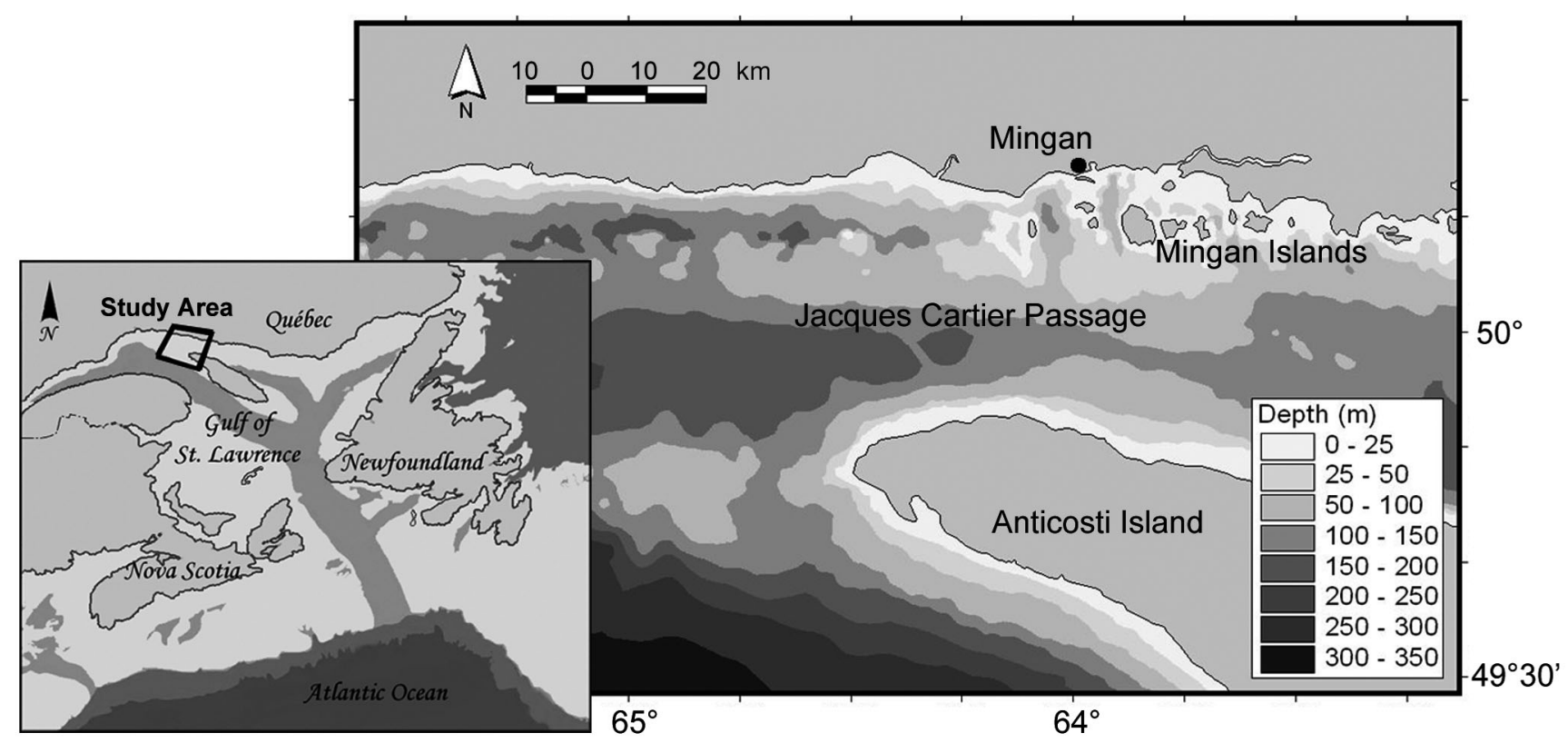

Fig. 1. Atlantic coast of Canada showing location of study area and main bathymetric contours

individuals being sighted several times in the same observation day, we used photo-identification techniques to retain only the first sighting of each individual in the analysis.

Satellite data were received from the National Oceanic and Atmospheric Administration (NOAA), processed by the Remote Sensing Laboratory of the Maurice Lamontagne Institute and then published using the St. Lawrence Observatory web site (www. osl.gc.ca). Raw data received each day from the 'advanced very high resolution radiometer' (AVHRR) were transformed into SST maps covering the entire Gulf of St. Lawrence using Terascan $^{\mathrm{TM}}$ software. Images were geo-referenced automatically using coastline recognition. Temperatures were calculated using a split-window algorithm (McClain et al. 1985).

Data mapping and identification of thermal fronts. For our analysis, we used data obtained on days for which a good quality satellite map of SST was available (with no clouds masking the study area) and for which weather conditions permitted field surveys. For each of these observation days, a GIS coverage was built by plotting the sightings on a map projected in Universal Transverse Mercator with a central meridian of $-63^{\circ}$ longitude, using ArcView 3.1 software with the 'spatial analyst' and the 'animal movement' extensions (Hooge \& Eichenlaub 1997). Satellite images of SST were incorporated into the GIS as raster (cell-based) layers. Pixels measured $1.132 \mathrm{~km}$ and were calibrated to temperature values in intervals of $0.256^{\circ} \mathrm{C}$. Fronts are usually defined as 'narrow regions where horizontal gradients are large' (Mann \& Lazier 1991) but definitions vary with respect to the strength of the gradient. For Ullman \& Cornillon (1999), each front represented a change in $\mathrm{SST}>0.375^{\circ} \mathrm{C} \mathrm{km}^{-1}$. In contrast, Marchand et al. (1999) observed fronts in the Estuary of the St. Lawrence with typical temperature gradients of 2 to $5^{\circ} \mathrm{C}$ over a few kilometres. We identified temperature gradients on each SST map by applying a Laplace filter to a series of circular matrices of 3 pixels in diameter. The centre pixel of each matrix returned data on the range of temperature values across that matrix. This edge-detection filter can identify fronts in any direction. Preliminary analysis showed that the average temperature gradient in our data set was $0.58^{\circ} \mathrm{C} \mathrm{km}^{-1}(\mathrm{SD}=0.65)$. Gradients of $1.88^{\circ} \mathrm{C} \mathrm{km}^{-1}$ thus represented 2 standard deviations above the mean. Based on this, we decided to define SST fronts as gradients of $2^{\circ} \mathrm{C} \mathrm{km}^{-1}$, which represented only the strongest temperature gradients.

Statistical analyses. We used a random resampling approach (Manly et al. 2002) to test the null hypothesis that whale sightings were distributed randomly with respect to thermal fronts. For each year, we drew the minimum convex polygon (MCP) containing $95 \%$ of our effort tracks. We used a land mask to remove the shape of the landmasses and created a buffer of $500 \mathrm{~m}$ around the shorelines to ensure that the polygon represented available habitat for whales (Fig. 2). For each observation day, we plotted random points within the MCP representing the study area of that year, in equal number to whale sightings. This ensured that random points fell in areas that were well covered by our survey effort. We then calculated the Euclidean distance 


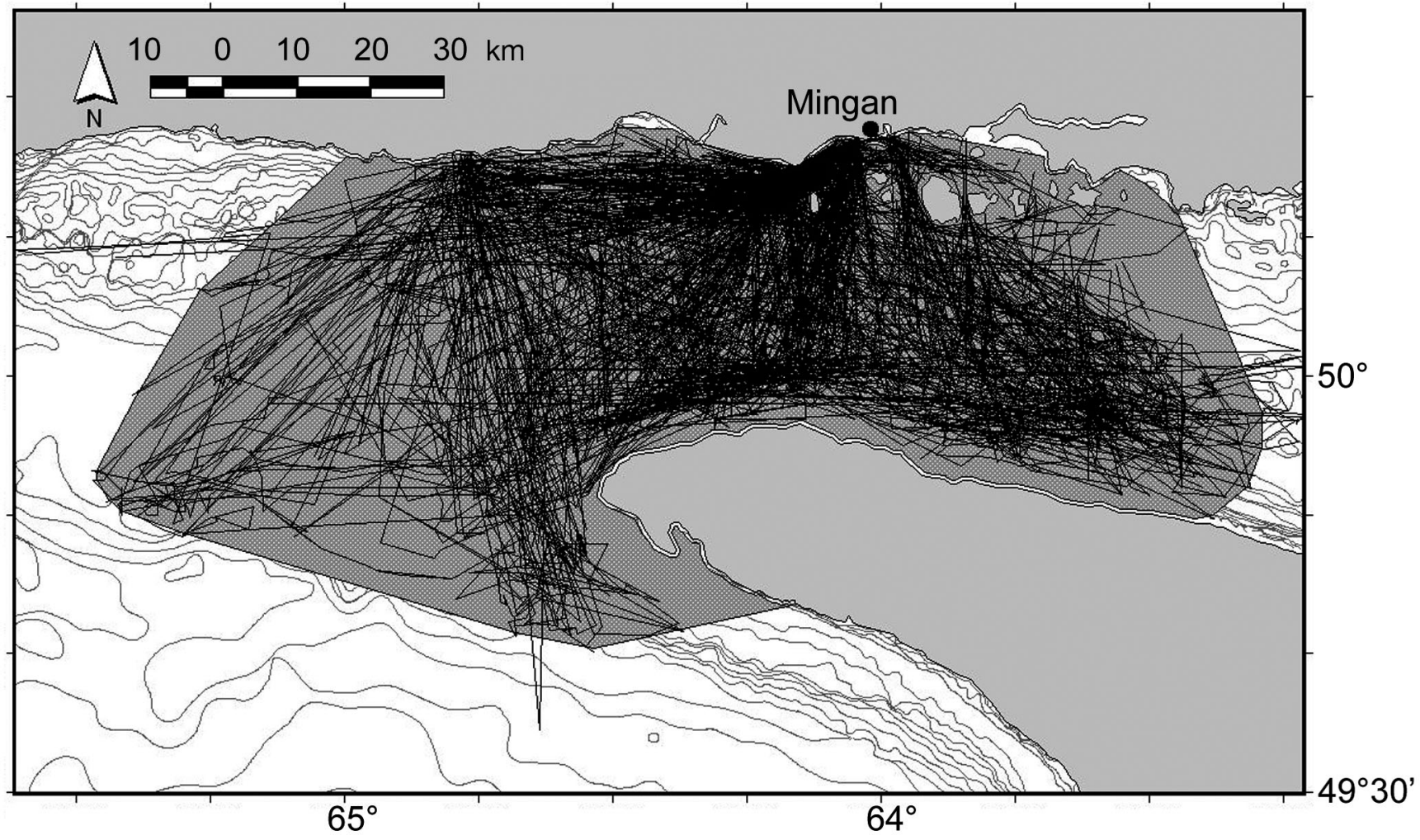

Fig. 2. Study area, showing track lines used during boat surveys over 1996 to 2000 period (black lines) and marine part of minimum convex polygon containing $95 \%$ of survey tracks (grey shading)

to the closest front for each of the random points and whale sightings. For each species, we pooled the data by month and by year and compared the average distances for random points and whale sightings using an ANOVA. We used post-hoc $t$-tests to compare each species with the random sample separately.

Resampling tests do not address the fact that environmental variables are usually correlated with each other as well as spatially autocorrelated (Schick \& Urban 2000). Parametric tests assume independence between data points but, in our case, because of spatial autocorrelation, 2 sightings that are close to each other have more similar characteristics than sightings that are further apart. Data cells are therefore not independent and this can increase Type I errors (some relationships appear significant when they are not). As recommended by Schick \& Urban (2000), we used Mantel tests to assess the correlation between whale locations and environmental variables while at the same time taking into account the spatial autocorrelation of these variables. Mantel tests differ from standard parametric regression techniques in that the dependent variables are dissimilarity matrices, and the test measures the degree of pairwise similarity between sets of data (Mantel 1967). Significance is evaluated via permutation procedures. A simple Mantel test asks whether locations that are similar in terms of the predictor variable (distance to front) are also similar in terms of the dependent variable (whale presence or absence). A partial Mantel test also considers space (geographic location) as a predictor variable, testing whether samples that are close in space have similar values for other variables. The power of this test is its ability to partial effects of confounding variables (Legendre \& Legendre 1998). The Mantel $\mathrm{r}^{2}$ are based on the normalised value $r$ of the Mantel statistic $z$. This standardized value rescales the statistic to the range of a conventional correlation coefficient bounded on $[-1,1]$.

We constructed 6 dissimilarity matrices, all of them generated from the positions of all random points and whale sightings; 1 matrix was constructed for space (Euclidean distance between sightings), 1 for the distance to fronts, and 1 for each species of whale. For the distance to fronts, we used the D15 dissimilarity index, which has the advantage of normalising the distance by the largest difference across the study area (Legendre \& Legendre 1998). For whales, we used group contrast matrices, where similar sites (i.e. 2 random points or 2 whale sightings) had a contrast value of 0 , and dissimilar sites (i.e. at the intersection of a random point and a whale sighting) had a contrast value of 1 . We then used simple and partial Mantel tests for each 
combination of these matrices, using 10000 iterations to assess significance. We performed analyses using the $\mathrm{R}$ package for multivariate and spatial analysis, Version 4.0 (Casgrain \& Legendre 2001).

\section{RESULTS}

\section{Observation days and whale sightings}

SST images were available on an irregular basis due to the frequency of images with heavy cloud cover obscuring the region; 61 observation days matched both requirements of a good quality satellite map and weather conditions permitting field surveys. These days were distributed homogeneously over the $5 \mathrm{yr}$ of the study but not over the 4 mo of the field season (Table 1). June and August were consistently underand over-represented, respectively, in the analysed data set. The 61 observation days available for analysis represented 1094 sightings of rorquals: 43 blue, 321 finback, 419 humpback and 311 minke whales. These are the first sightings of the whales seen on each day. Sightings from different dates can include the same individuals. Fig. 3 shows that whale sightings were not distributed homogeneously within the survey effort.

\section{Distribution of whales with respect to thermal fronts}

Temperature gradients observed in satellite maps were often steep (frequently $>2{ }^{\circ} \mathrm{C} \mathrm{km}^{-1}$ ) indicating the occurrence of strong mesoscale oceanographic processes. Whales were located closer to thermal fronts than expected from a random distribution (ANOVA, $\left.F_{4}=7.45, \mathrm{p}<0.001\right)$. We illustrate this relationship and the temporal variability of surface fronts in Fig. 4 . The pattern of SST and frontal areas on 2 September, 2000 (Fig. 4A,B) is characteristic of a wind-induced up-

Table 1. Distribution across years and months of suitable observation days in the northern Gulf of St. Lawrence between 1996 and 2000. Observation days suitable for analysis satisfied 2 requirements: availability of a good satellite map of sea surface temperature and weather conditions permitting field surveys

\begin{tabular}{|lcrrrc|}
\hline Year & Jun & Jul & Aug & Sep & All months \\
\hline 1996 & 1 & 4 & 5 & 3 & 13 \\
1997 & 0 & 2 & 3 & 4 & 9 \\
1998 & 2 & 3 & 4 & 2 & 11 \\
1999 & 3 & 2 & 5 & 5 & 15 \\
2000 & 1 & 3 & 6 & 3 & 13 \\
All years & 7 & 14 & 23 & 17 & 61 \\
\hline
\end{tabular}

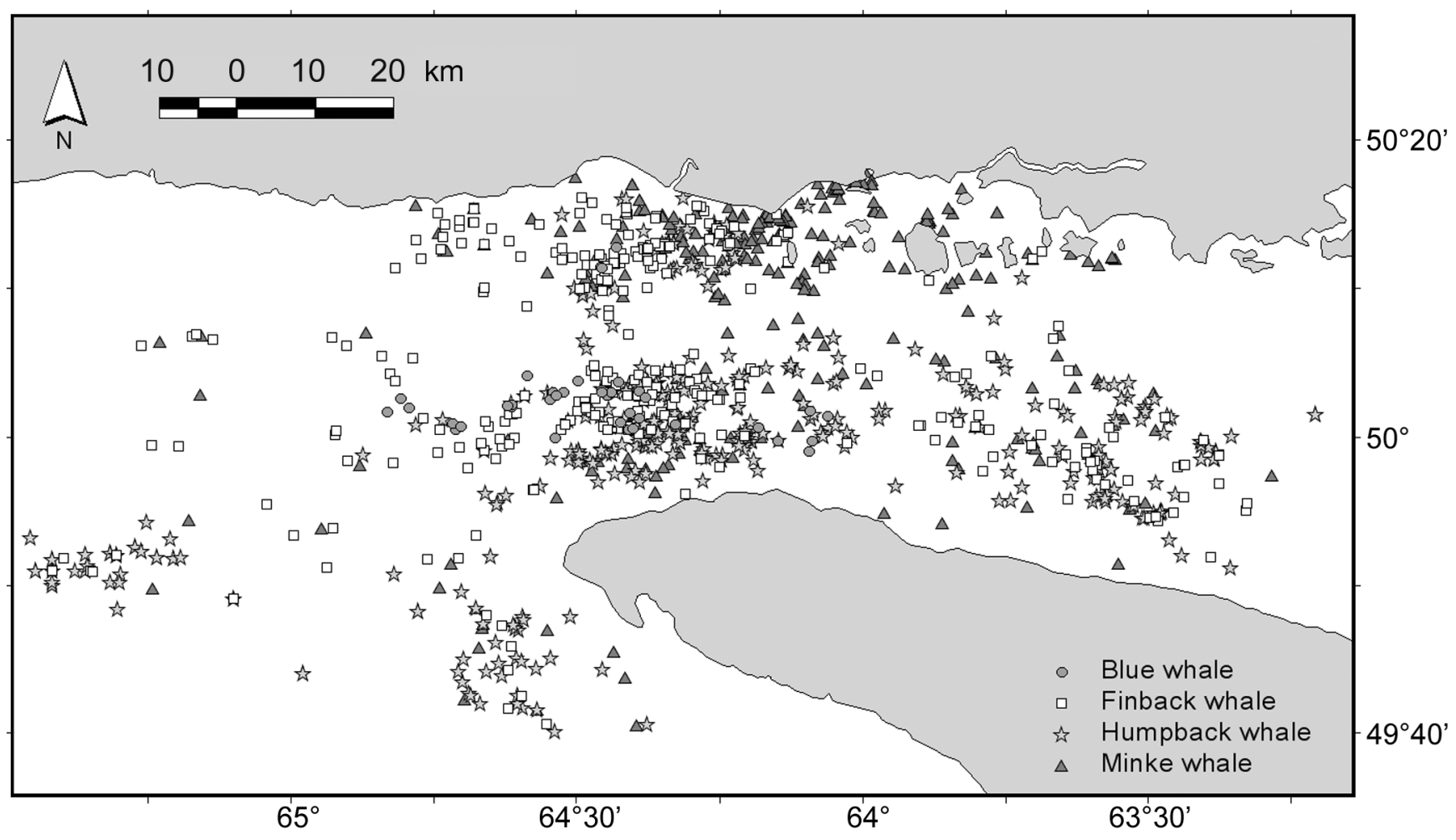

Fig. 3. Balaenoptera musculus, B. physalus, Megaptera novaeangliae and B. acutorostrata. Distribution of blue (n = 43), finback $(\mathrm{n}=321)$, humpback $(\mathrm{n}=419)$ and minke $(\mathrm{n}=311)$ whale sightings used in our analysis of habitat selection by rorqual whales over 1996 to 2000 observation period 

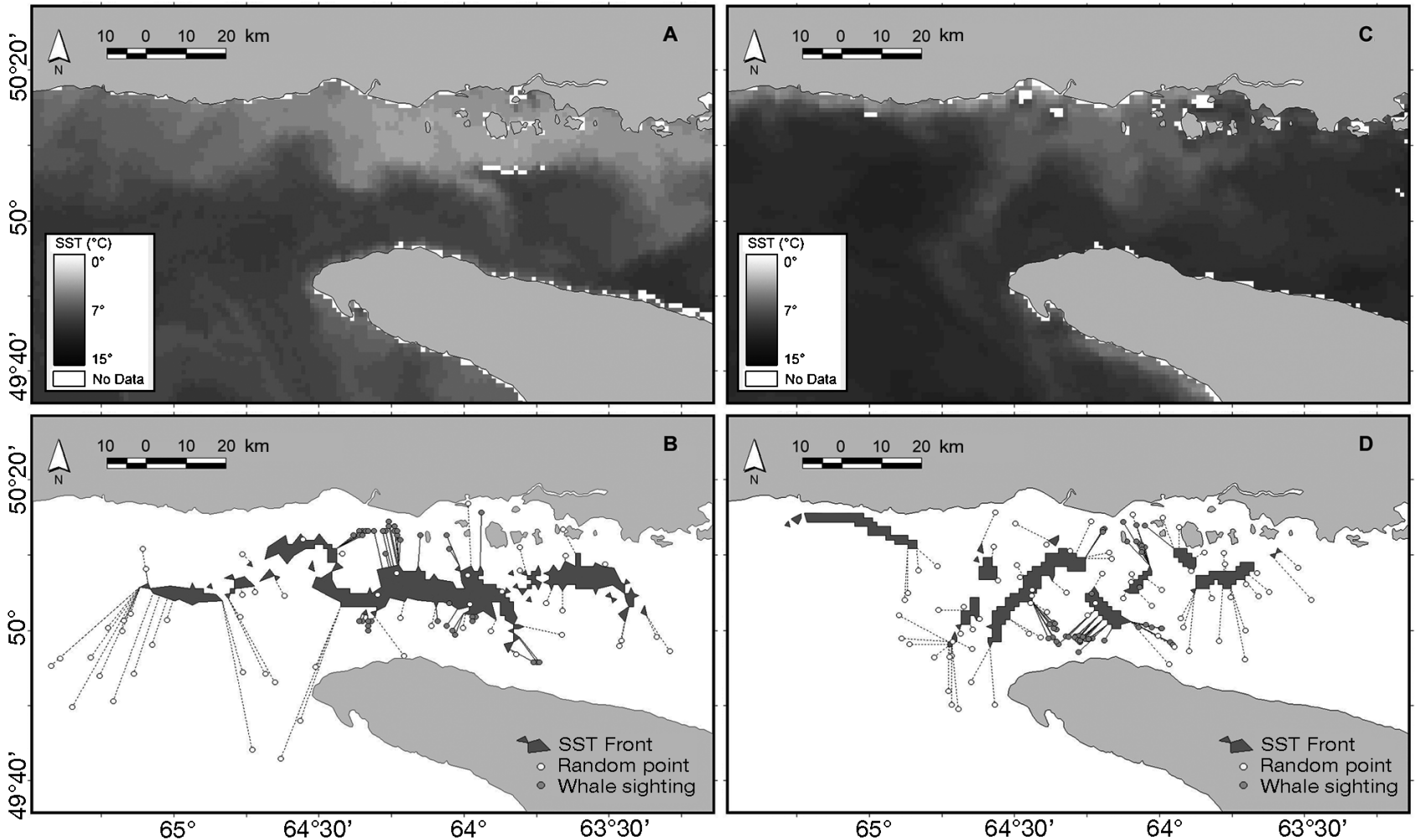

Fig. 4. Sea surface temperature (SST), location of frontal areas, whale sightings (O), random points (O) and shortest straight lines linking sightings or random points to the closest thermal front. (A) SST map dated 2 September 2000 and (B) associated SST fronts typical of upwellings induced by westerly winds; (C) SST map dated 23 August 2000 and (D) associated SST fronts typical of tidally induced upwellings. Specific names as in Fig. 3 legend

welling with fronts lying in a general east-west axis. The configuration on 23 August, 2000 (Fig. 4C,D) shows the typical result of tidal forces with discontinuous irregular fronts, some of them in a north-south axis. Post-hoc $t$-tests showed that the relationship between whales and thermal fronts was not the same for all species: the difference between whale sightings and random points was statistically significant for blue $\left(t_{84}=8.41, \mathrm{p}<0.001\right)$, finback $\left(t_{640}=5.91, \mathrm{p}<0.001\right)$ and humpback $\left(t_{836}=6.87, \mathrm{p}<0.001\right)$, whales but marginally non-significant for minke whales $\left(t_{620}=1.79, \mathrm{p}=\right.$ 0.08). On average, blue whales were the closest to the fronts, followed by humpback, finback, minke whales and random points. This order remained remarkably stable over the 4 mo of the study (Fig. 5), except in July when finback whales were found slightly closer to the frontal areas than humpback whales. Each species was farther away from the fronts in June than in any other month, which was also true of the random points.

Simple Mantel tests between space and the other matrices showed strong spatial autocorrelations for all species of whales as well as for the SST fronts (Table 2). Simple Mantel tests also showed significant correlations between the SST front matrix and all 4 whale matrices, confirming the results of the resam- pling test: points that were similar in terms of whale presence were also similar in their distance to the frontal areas. A partial Mantel test showed that there was a significant effect of the distribution of SST fronts on distribution of blue (Mantel partial $\mathrm{r}^{2}=0.19, \mathrm{p}<$ $0.01)$, finback $\left(r^{2}=0.13, p<0.05\right)$ and humpback $\left(r^{2}=\right.$

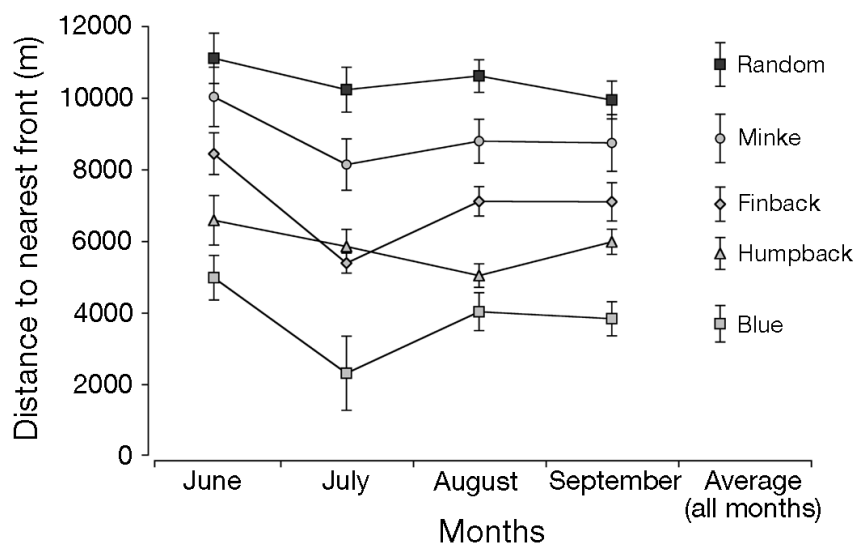

Fig. 5. Balaenoptera musculus, B. physalus, Megaptera novaeangliae and $B$. acutorostrata. Mean $( \pm \mathrm{SE})$ distances between whale sightings or random points and the nearest frontal area for years 1996 to 2000 
Table 2. Balaenoptera musculus, B. physalus, Megaptera novaeangliae and $B$. acutorostrata. Mantel $\mathrm{r}$ coefficients and p-values for results of simple and partial Mantel tests between dissimilarity matrices representing space, distance to nearest front and presence/absence of each species of whale during a 5 yr study in the northern Gulf of St. Lawrence (1996 to 2000). Space: spatial autocorrelation; Fronts: correlations between whale distribution patterns and sea surface temperature fronts

\begin{tabular}{|lccc|}
\hline & \multirow{2}{*}{$\begin{array}{c}\text { Space } \\
\text { Simple test }\end{array}$} & Simple test & Pronts \\
\cline { 3 - 4 } & & - & - \\
Fronts & $0.35(\mathrm{p}<0.001)$ & $0.25(\mathrm{p}<0.01)$ & $0.19(\mathrm{p}<0.01)$ \\
Blue & $0.14(\mathrm{p}<0.01)$ & $0.22(\mathrm{p}<0.01)$ & $0.13(\mathrm{p}<0.05)$ \\
Finback & $0.21(\mathrm{p}<0.01)$ & $0.16(\mathrm{p}<0.01)$ & $0.12(\mathrm{p}<0.05)$ \\
Humpback & $0.07(\mathrm{p}<0.01)$ & $0.11(\mathrm{p}<0.05)$ & $0.07(\mathrm{p}=0.11)$ \\
Minke & $0.49(\mathrm{p}<0.001)$ & & \\
\hline
\end{tabular}

Our results suggest that frontal areas create attractive foraging conditions for rorquals. Most fronts in the St. Lawrence result from tide- or wind-induced upwellings (Koutitonsky \& Bugden 1991). These upwellings increase biological productivity (Olson \& Backus 1985), which might alone explain the attractiveness of such areas to large whales. However, the location of SST fronts can vary quickly among days. Because we worked at the time-scale of single days, we believe that the link we observed between whale and front distribution cannot be explained solely by this increased productivity. Another explanation is that

$0.12, \mathrm{p}<0.05)$ whales even once spatial autocorrelation was accounted for, but not in the case of minke whales $\left(r^{2}=0.07, p=0.11\right)$. This indicates that the correlation observed between SST fronts and minke whales in the simple Mantel test might have been due to their strongly autocorrelated spatial structure, whereas the spatial component was not the only explanation for the correlation found with the 3 other rorqual species.

Although statistically significant, most Mantel correlations were low. However, because of the randomisation technique involved, the magnitude of Mantel correlations are often comparatively small, even when highly significant statistically (Dutilleul et al. 2000) and should be interpreted with caution (Schick \& Urban 2000). The coefficient we used in the Mantel tests assumed that the functional relationships between species and habitat variables were linear. Although we did not test this assumption, a re-analysis of the minke whale data using a Spearman nonparametric coefficient in the Mantel test (Legendre \& Legendre 1998) yielded similar results and conclusions.

\section{DISCUSSION}

We combined a large data set of whale sightings with satellite images of SST to show that whale distribution was unambiguously dependent on frontal areas. Blue, finback and humpback whales were closer to thermal fronts than expected under a random scenario, whereas minke whales were not. This important patterning effect of the SST fronts on the distribution of whales was robust enough to be maintained even once spatial autocorrelation was taken into account. To our knowledge, this fine-scale spatial relationship between fronts and rorqual whales is shown here for the first time, but is similar to a larger scale relationship between humpback whales and a coastal upwelling front in the California Current System (Tynan et al. 2005). temperature gradients created by these upwellings can have a herding effect on krill and fishes along their edge. Krill forced upwards by the upwelling try to swim down to avoid the more intense light levels at the surface and their concentration increases, making them easier prey for their predators (Lavoie et al. 2000). Similarly, when capelin are exposed to temperature gradients, they concentrate within narrow thermal zones by avoiding the colder water (Marchand et al. 1999). Therefore, concentrations of krill and capelin can be expected at SST fronts, where cold waters limit their distribution. At the head of the Laurentian Channel for instance, location and timing of some capelin aggregations in the upper water column are predictable (Simard et al. 2002). Thus, whales have a higher probability of detecting dense patches of food and can minimise their foraging and travelling times by exploiting frontal areas. We believe that this herding effect and the predictability of such concentrations of prey items are the main reasons for the relationship we observed at such a small time-scale.

A potential source of bias in our study comes from the nature of our sampling design. Habitats where whale densities were highest were likely to have been oversampled because field operations aimed at maximising whale encounters, rather than ensuring that habitats were sampled equally or randomly. An artificial relation between whales and frontal areas could thus have been created if field workers were cuing on frontal areas to find whales. This, however, was not the case, since field personnel was uninformed about the position of fronts when leaving from the research station in the morning. In addition, potential biases when collecting data from platforms of opportunity are minimised by broad spatial and temporal coverage that incorporates a range of habitat variability (Evans \& Hammond 2004, Redfern et al. 2006), as was the case in this study. Like other studies based on platforms of opportunity or catch data (e.g. Weinrich et al. 2000, Gregr \& Trites 2001, Clapham et al. 2004), we thus 
assumed that if any strong ecological association did exist, we would be able to detect it despite the limitations of our design. It is also important to note that we compared used to available habitat, rather than used to unused habitat, so that we never assumed that unsampled habitat contained no whales. This approach is the most conservative way to estimate habitat selection (Manly et al. 2002).

Our results were consistent throughout the research season despite a potential seasonal bias in our methods. In June, temperature gradients are smaller because spring warming of the waters has not yet occurred. Thermal fronts might then be harder to detect using surface temperature and some of them might not reach our threshold value of $2^{\circ} \mathrm{C} \mathrm{km}^{-1}$. A smaller number of fronts at the surface would make all points appear farther away from the frontal areas and this could explain why mean distances to the nearest front were higher in June than in any other month. Because this was true for all species and for random points as well, we do not believe this is a biological difference.

Rorquals are sometimes observed feeding along front lines (R. Sears \& T. Doniol-Valcroze pers. obs.). In this study, most whales were observed closer to the fronts than expected under a random scenario but they were not directly on top of the frontal areas. Two hypotheses could explain this spatial lag. First, the fronts are not straight lines under the surface. They can deviate from a vertical line, and can sometimes originate several kilometres away from where they are detected at the surface. Thus the actual aggregation of prey items might be a certain horizontal distance away from the surface manifestation of the front. Second, aggregation of passive dispersing prey species by fronts may take time to develop (Olson \& Backus 1985, Podesta et al. 1993). This lag could explain the difference between the distribution of fronts as seen by the satellite and the distribution of whales observed from boats a few hours before or after.

The spatial and time lags mentioned above could explain why some studies of large baleen whales did not find relationships between whales and SST fronts. Such studies usually examine the value of the temperature gradient at the exact location of the whale sighting and not the distance to the nearest front (Baumgartner \& Mate 2005). In addition, they often use SST maps that have been averaged over several days (Hamazaki 2002). Alternatively, it is possible that different species (e.g. rorquals vs. right whales) show specific associations with thermal fronts, that study areas differ in the relative importance of thermal fronts to whales, or that results depend on the way thermal fronts are defined and identified. For these reasons, we believe that SST fronts constitute a complementary proxy for food availability, but that they might not be suitable in all cases. However, the benefits of this proxy are that it is one step closer to actual prey availability than many other oceanographic variables, and that it suggests plausible mechanisms for the observed spatial relationships.

Blue whales were found closer to SST fronts than any other whale species and, once spatial autocorrelation was taken into account, minke whales were not associated with fronts. We suggest 2 non-exclusive hypotheses to explain these differences among rorquals. First, blue whales are specialists and feed exclusively on krill. In contrast, humpback and finback whales have a more omnivorous diet in our study area, with some overlap between the 2 species (shown through analysis of fatty acids; Borobia et al. 1995). Because euphausiids are capable of less active horizontal movements, their aggregation patterns are probably more influenced by the concentrating effect of fronts than are those of fishes. Marchand et al. (1999) observed that the distribution patterns of capelin in the estuary of the St. Lawrence did not coincide exactly with the krill distribution, but the 2 total biomasses were significantly correlated. This could explain why humpback and finback whales, which feed on both krill and fishes, were observed farther away from the fronts and were not significantly different from each other. This hypothesis could only be tested with data on prey items at each sighting location. It would also be useful to know more about the diving profiles of the different species using data-recording tags. Second, in our study area, minke whales use shallower waters on average than other rorquals, their distribution is strongly linked to heterogeneous bottom relief (T. Doniol-Valcroze \& R. Sears unpubl. data) and they prefer certain substrates like sand dunes (Naud et al. 2003). Similarly, minke whales (as well as some finbacks) studied in the Bay of Fundy were attracted to high-vorticity regions of eddy habitats (Johnston et al. 2005). These results could reflect distinctive hunting techniques for which underwater topography and tidally-induced features are important (Hoelzel et al. 1989), explaining why the relationship between fronts and minke whales was very weak.. This hypothesis could be tested with a multivariate model that would include all of these variables and compare their relative importance for minke whales. Overall, these observations suggest a finer degree of habitat partitioning among rorqual species on their feeding grounds than had been previously suspected.

The spatial autocorrelation values for the 4 species (Table 2) show that the whales with the least amount of spatial structure are the ones most highly correlated with fronts. In contrast, minke whales are the most spatially autocorrelated, yet there is no observed relationship to fronts, which emphasises the need to 
identify other variables which could be contributing to these spatial patterns. We also observed that using partial instead of simple Mantel tests slightly diminished the significance of the relationship with fronts, suggesting that the spatial autocorrelation present in our data could represent the effect of other, unknown, variables.

In conclusion, our study confirms that habitat selection by rorqual whales cannot always be explained solely by looking at the absolute values of environmental parameters. Our results show that SST fronts can have a strong influence on the distribution of rorquals and could explain part of the temporal variability that cannot be addressed by static factors. We strongly encourage other studies of habitat use by marine mammals to include such dynamic variables in their models, especially when data on prey distribution are not available. We also found significant differences between the 4 rorqual species in relation to the frontal areas, indicating a fine degree of habitat partitioning that deserves more research. We believe these results can help identify habitats important to whales and can prove critical for management decisions.

Acknowledgements. Many thanks to all Mingan Island Cetacean Study team members for their long-term data collecting efforts and to all who have supported our work over the years. Also special thanks to D. E. Sergeant and M. Humphries for their help, and to 3 anonymous reviewers for their constructive comments. We thank D. Hauser for her advice and trust. We acknowledge a fellowship given to T.D.-V. by the J. W. McConnell foundation.

\section{LITERATURE CITED}

Baumgartner MF, Mate BR (2005) Summer and fall habitat of North Atlantic right whales (Eubalaena glacialis) inferred from satellite telemetry. Can J Fish Aquat Sci 62:527-543

Baumgartner MF, Cole TVN, Clapham PJ, Mate BR (2003) North Atlantic right whale habitat in the lower Bay of Fundy and on the SW Scotian Shelf during 1999-2001. Mar Ecol Prog Ser 264:137-154

Benson SR, Croll DA, Marinovic BB, Chavez FP, Harvey JT (2002) Changes in the cetacean assemblage of a coastal upwelling ecosystem during El Nino 1997-98 and La Nina 1999. Prog Oceanogr 54:279-291

Bjørge A (2002) How persistent are marine mammal habitats in an ocean of variability? In: Evans PGH, Raga JA (eds) Marine mammals: biology and conservation, Kluwer Academic/Plenum Publishers, New York, p 63-91

Borobia M, Gearing PJ, Simard Y, Gearing JN, Beland P (1995) Blubber fatty-acids of finback and humpback whales from the Gulf of St-Lawrence. Mar Biol 122:341-353

Casgrain P, Legendre P (2001) The R package for multivariate and spatial analysis, Version $4.0 \mathrm{~d} 6$, User's manual, Département de Sciences Biologiques, Université de Montréal

Clapham PJ, Good C, Quinn SE, Reeves RR, Scarff JE, Brownell RL Jr (2004) Distribution of North Pacific right whales (Eubalaena japonica) as shown by 19th and 20th century whaling catch and sighting records. J Cetacean Res Manage 6:1-6

Croll DA, Marinovic B, Benson S, Chavez FP, Black N, Ternullo R, Tershy BR (2005) From wind to whales: trophic links in a coastal upwelling system. Mar Ecol Prog Ser 289: $117-130$

Davis RW, Ortega-Ortiz JG, Ribic CA, Evans WE and 6 others (2002) Cetacean habitat in the northern oceanic Gulf of Mexico. Deep-Sea Res I 49:121-142

Dutilleul P, Stockwell JD, Frigon D, Legendre P (2000) The Mantel test versus Pearson's correlation analysis: assessment of the differences for biological and environmental studies. J Agric Biol Environ Stat 5:131-150

Evans PGH, Hammond PS (2004) Monitoring cetaceans in European waters. Mammal Rev 34:131-156

Fiedler PC, Bernard HJ (1987) Tuna aggregation and feeding near fronts observed in satellite imagery. Cont Shelf Res 7: $871-881$

Gaskin DE (1987) Updated status of the right whale, Eubalaena glacialis, in Canada. Can Field-Nat 101:295-309

Gregr EJ (2004) Modeling species-habitat relationships in the marine environment - a comment on Hamazaki (2002). Mar Mamm Sci 20:353-355

Gregr EJ, Trites AW (2001) Predictions of critical habitat for five whale species in the waters of coastal British Columbia. Can J Fish Aquat Sci 58:1265-1285

Hamazaki T (2002) Spatiotemporal prediction models of cetacean habitats in the mid-western North Atlantic Ocean (from Cape Hatteras, North Carolina, USA to Nova Scotia, Canada). Mar Mamm Sci 18:920-939

Hilborn R, Mengel M (1997) The ecological detective-confronting models with data. Princeton University Press, Princeton, NJ

Hoelzel AR, Dorsey EM, Stern SJ (1989) The foraging specializations of individual minke whales. Anim Behav 38: 786-794

Hofmann EE, Powell TM (1998) Environmental variability effects on marine fisheries: four case histories. Ecol Appl 8:S23-S32

Hooge PN, Eichenlaub B (1997) Animal movement extension to Arcview. Alaska Biological Science Center, US Geological Survey, Anchorage, AK

Hui CA (1985) Undersea topography and the comparative distributions of 2 pelagic cetaceans. Fish Bull (Wash DC) 83: $472-475$

Johnston DW, Thorne LH, Read A (2005) Fin whales Balaenoptera physalus and minke whales Balaenoptera acutorostrata exploit a tidally driven island wake ecosystem in the Bay of Fundy. Mar Ecol Prog Ser 305:287-295

Kingsley MCS, Reeves RR (1998) Aerial surveys of cetaceans in the Gulf of St. Lawrence in 1995 and 1996. Can J Zool $76: 1529-1550$

Koutitonsky VG, Bugden GL (1991) The physical oceanography of the Gulf of St. Lawrence: a review with emphasis on the synoptic variability of the motion. Can Spec Publ Fish Aquat Sci 113:57-90

Lavoie D, Simard Y, Saucier FJ (2000) Aggregation and dispersion of krill at channel heads and shelf edges: the dynamics in the Saguenay-St. Lawrence Marine Park. Can J Fish Aquat Sci 57:1853-1869

Legendre P, Legendre L (1998) Numerical ecology. Elsevier Science, Amsterdam

Manly BFJ, McDonald LL, Thomas DL, McDonald TL, Erickson WP (2002) Resource selection by animals: statistical design and analysis for field studies, 2nd edn. Kluwer Academic Publishers, Dordrecht 
Mann KH, Lazier JRN (1991) Dynamics of marine ecosystems: biological-physical interactions in the oceans. Blackwell Scientific Publications, Oxford

Mantel NA (1967) The detection of disease clustering and a generalized regression approach. Cancer Res 27:209-220

Marchand C, Simard Y, Gratton Y (1999) Concentration of capelin (Mallotus villosus) in tidal upwelling fronts at the head of the Laurentian Channel in the St. Lawrence estuary. Can J Fish Aquat Sci 56:1832-1848

McClain EP, Pichel WG, Walton CC (1985) Comparative performance of AVHRR-based multichannel sea surface temperatures. J Geophys Res 90:11587-11601

Murase H, Matsuoka K, Ichii T, Nishiwaki S (2002) Relationship between the distribution of euphausiids and baleen whales in the Antarctic (35 degrees E-145 degrees W). Polar Biol 25:135-145

Murison LD, Gaskin DE (1989) The distribution of right whales and zooplankton in the Bay of Fundy Canada. Can J Zool 67:1411-1420

Naud MJ, Long B, Brethes JC, Sears R (2003) Influences of underwater bottom topography and geomorphology on minke whale (Balaenoptera acutorostrata) distribution in the Mingan Islands (Canada). J Mar Biol Assoc UK 83: 889-896

Olson DB, Backus RH (1985) The concentrating of organisms at fronts: a cold-water fish and a warm-core Gulf Stream ring. J Mar Res 43:113-137

Podesta GP, Browder JA, Hoey JJ (1993) Exploring the association between swordfish catch rates and thermal fronts on United-States longline grounds in the Western NorthAtlantic. Cont Shelf Res 13:253-277

Editorial responsibility: Otto Kinne (Editor-in-Chief), Oldendorf/Luhe, Germany
Redfern JV, Ferguson MC, Becker EA, Hyrenbach KD and 15 others (2006) Techniques for cetacean-habitat modeling. Mar Ecol Prog Ser 310:271-295

Schick RS, Urban DL (2000) Spatial components of bowhead whale (Balaena mysticetus) distribution in the Alaskan Beaufort Sea. Can J Fish Aquat Sci 57:2193-2200

Simard Y, Lavoie D, Saucier FJ (2002) Channel head dynamics: capelin (Mallotus villosus) aggregation in the tidally driven upwelling system of the Saguenay St. Lawrence Marine Park's whale feeding ground. Can J Fish Aquat Sci 59:197-210

Thibault B, Larouche P, Dubois JMM (2002) Variability of hydrodynamic phenoma of the Upper St. Lawrence estuary using Landsat 5 thematic mapper data. Int J Remote Sens 23:511-524

Tynan CT, Ainley DG, Barth JA, Cowles TJ, Pierce SD, Spear LB (2005) Cetacean distributions relative to ocean processes in the northern California Current System. DeepSea Res II 52:145-167

Ullman DS, Cornillon PC (1999) Satellite-derived sea surface temperature fronts on the continental shelf off the northeast US coast. J Geophy Res C 104:23459-23478

Weinrich MT, Kenney RD, Hamilton PK (2000) Right whales (Eubalaena glacialis) on Jeffreys Ledge: a habitat of unrecognized importance? Mar Mamm Sci 16:326-337

Whitehead H, Carscadden JE (1985) Predicting inshore whale abundance - whales and capelin off the Newfoundland coast. Can J Fish Aquat Sci 42:976-981

Woodley TH, Gaskin DE (1996) Environmental characteristics of North Atlantic right and fin whale habitat in the lower Bay of Fundy, Canada. Can J Zool 74:75-84

Submitted: November 24, 2005; Accepted: July 20, 2006 Proofs received from author(s): March 26, 2007 